\title{
Implications of COVID-19 Pandemic for Higher Education Institutions' Emergency Preparedness, Response and Recovery Mechanism (EPRRM) Contingency Plan: Relating Issues to Tanzania
}

\author{
Reuben Bihu
}

reubimon@gmail.com

\begin{abstract}
The COVID-19 Pandemic began in China at the end of 2019 and spread rapidly to become a global pandemic by the first quarter of 2020. Many death incidences were reported in a short time before it was being familiar to many nations in terms of practices for containment. In response, many countries had to close down education institutions, lockdown cities, and countries, and emphasize practices of new lifestyles and behaviors thought to guarantee safety. Eventually, students were the most affected groups among the nations. Particularly, the impacts of the pandemic were realized in the teaching and learning processes as well as changes in the practices of administration and management of education services. The impacts were essentially felt by students themselves, professors, instructors, teachers, and educationists in managerial and administrative positions. The high intensities of the impacts escalated as there were no contingency plans to curb the sudden changes and lethality in the instant period of pandemic encounters. The pandemic situation signified the demand for an emergence preparedness, response, and recovery mechanism (EPRRM) contingency plan to be put in place for systems of education. The education EPRRM contingency plan would assist the education machinery in higher learning institutions (HLIs) and other levels of learning to keep in resilient and continuant teaching and learning processes in times of crises.
\end{abstract}

\section{Keywords}

COVID-19 Impacts, Teaching, Learning, Administration and management, Higher Learning Institutions, Emergence, Preparedness, Response, Recovery

\section{Introduction}

The outbreak of the coronavirus disease in 2019 (COVID-19 disease) in Wuhan City at the end of 2019 and its spread as a global pandemic marked into the new world era threatening the human population. It affected global life systems in a very short time of about 3 to 4 months. Of course, by March 2020 educational institutions were once closed due to eruption and rapid spread of the pandemic due to high death rates across nations. After re-opening the institutions with some guidelines into the new normal (Prahani \& Cheng, 2020), serous epidemiological control measures were taken from facial epithelial masking, social distancing, hygienic to hospitalization practices for controlling the spread of the viruses. However, the involvement of the education machinery in the response to the situation was inadequate. In particular, education sectors in systems of governments of both high-income countries (HICs) and low-income countries (LICs) including Tanzania either lacked adequate or were in total lack of the education EPRRM contingency plan before the pandemic. The viruses seriously opened new thinking toward physical and social human interaction, marked as a risky matter that confronted human health than had ever been in the most recent history of man. This study analyses the impacts the pandemic caused to the processes of teaching, learning, and administration in higher learning institutions (HLIs), and the relevance of the education EPRRM contingency plan. The paper is therefore organized in the form of introduction, study framework, methodology, results, conclusion, and recommendations. 


\section{The Study Framework}

The education sector's performance is determined by the operationalization of the policies and relevant provisions at the institutional or classroom levels. Particularly, the effectiveness and efficiency of systems operating to give education output and outcome at the institutional levels are determined by human resources. As active resources, teachers and instructors as well as students exhibit unique dispositions to teaching and learning in times of emergencies and crises, the management of which can be explained by the contingency theoretical perspective. The contingency approach to management is a school of thought on planning and management regarding people's motivation toward an endeavour in particular circumstances which may confront their wellbeing and performance. According to the contingency approach, there is no best way to manage, it depends on the circumstances (Luthans \& Stewart, 1977; Suleiman et al., 2018). The contingency approach assesses the functioning of the institutions concerning the needs of particular members and the external pressure facing them (Galabawa, 2001). Maslow's (1943) hierarchy of needs theory put that individuals acquire physiological safety, affection, esteem, and self-actualization needs, strictly in that order, for their motivation, satisfaction, and continuance. It implies that physiological safety needs related to health and social affection, for example, could prevent the acquisition and attainment of higher-level needs of esteem and self-actualization. The needs concept is correlated to organizational performance. The Geren's (n.d.) analysis on reconstructing the content factors to match a global common needs and varied values, presents that the needs' hierarchy lacks universal applicability, and scholars like Kispál-Vitai (2016) seem to support the critique arguing that, Maslow's framework is relevant intuitively and that research was not able to validate it. However, the needs hierarchy holds significant applications in organizational motivation schemes, where flexibility is allowable to reflect organizational contextual needs (Kroth, 2007). Herzberg's duo-factor theory (Tan, 2013) tried to mend the methodological gap in Maslow's (1943) needs hierarchy using empirical evidence from the feelings of the engineers and accountants from nine companies in the USA in 1959 (Owler \& Morrison, 2015). According to the evidence, good feelings are related to job content or motivators and bad feelings are associated with job context or hygiene. Implicitly, factors built into the job itself, on one hand, causing workers' job satisfaction including achievement, responsibility, recognition, advancement, the possibility of growth, and nature of work, are quite different from those contributing to job dissatisfaction. Such intrinsic factors may cause educationists to clingy to massive teaching and learning regardless of adversity of disastrous working situation, or vice versa. On the other hand, good hygienic factors related to work policy and administration, supervision, human relations, salary security, personal life, working conditions, and good status do not motivate if present, but if absent create job dissatisfaction (Vero, 2017; Yudhvir \& Sunita, 2012). The contingency view would appraise the managerial response on factors contingent on the organization's routines.

The pandemic imposed significant effects in both content and contextual or hygienic factors influencing motivation, satisfaction, and continuance in the education arena. Particularly, institutions' infrastructures, operations, learners, teachers and instructors, and other workers including those in management were subjected to COVID-19 impacts, in the duo-factor position. The duo-factor theoretical model reminds us of the necessity of the education EPRRM contingency plan to contain and control the adverse impacts of the emergences. The Education EPRRM model for action encompasses different types of machinery' participation from national systemic to 
institutional levels (Figure 2:1). This model draws from the Sendar's Framework for disaster risk reduction (World Bank \& GFDRR, 2019), which emphasizes the safety and protection of learners from social, political, economic, environmental, and health-related issues. Within the model, the assessments, policy development, and planning processes are macro-level tasks implemented to ensure that structures, systems, and conditions are put in place to address education sector needs to respond to emergencies. The tasks are handed down in a relevant contingency plan to control emergencies and crises in education. The contingency plan calls for allowable administrative and managerial flexibility in times of contingencies. It essentially guides for acquisition and maintenance of standby physical and soft infrastructures to ensure that all educational facilities are accessible, safe, and by all means, possibly protect students from hazards and all potential forms of harm in cases of emergencies and crises. In this case, engagement, coordination, and communication ensure roles and responsibilities are understood by responsible parties, and stakeholders are positioned to deliver on agreed actions. In this framework, capacity and capability key actors and stakeholders ensure sufficient resources are allocated to needs, and that stakeholders have the skills to deliver them. Through teaching and learning the education sector leaders and teachers build knowledge, skills, and behaviours that reduce risk and prevent potential harm to all students on one hand and service providers on the other hand. For the prime purpose and intent, each action level should consider the three-phase priority of preparedness, response, and recovery in its framework. In technical implications, the preparedness phase provides a medium-term goal of development and planning to improve and sustain education sector resilience, the recovery phase provides a short-term goal to restore the basic functions of the education system, and the response phase provides an immediate goal to restore educational access to all affected students. This interactive inclusive framework gears for recovery and resilience important for the continuance of educational programs.

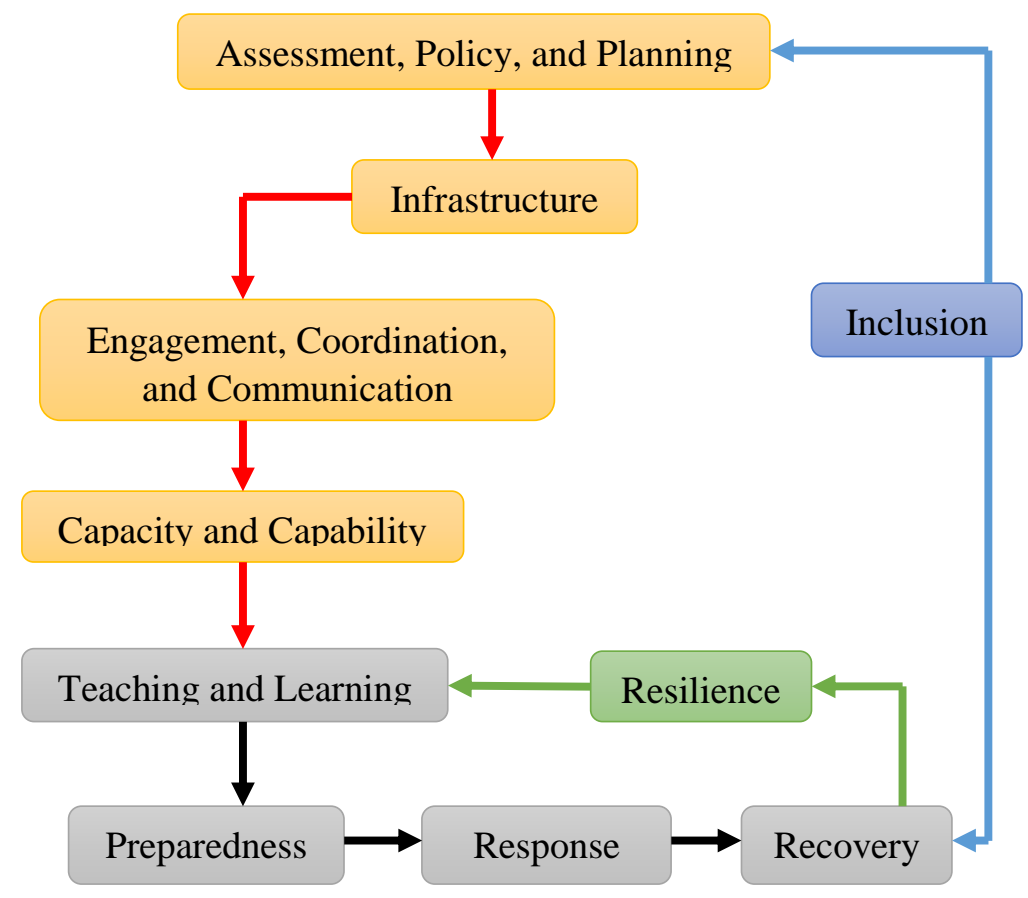

Figure 2:1 The education EPRRM model. Adapted from World Bank and GFDRR (2019) 


\section{Methodology}

This literature research used secondary data on COVID-19 impacts on teaching, learning, and administration of education in different countries, and the reflection to Tanzania, particularly, on the necessity of the Higher Learning Institutions' (HLIs') education EPRRM contingency plan. The review process was done using Zotero Computer software based on the thematic questions under the study. Specifically, scholarly works used in the study were gathered based on the phrases containing study keywords including "COVID-19 Impacts on Teaching", "COVID-19 Impacts on Learning", "COVID-19 Impacts on Educational Institution Administration", and "Preparedness, Response and Recovery" published on different countries across Africa, Europe, Asia and the USA for 2020 and 2021. Analysis was done by grouping similar findings on each thematic area herein identified as constructs, and with the reflective argument on the education EPRRM contingency plan focus. The literature search and library building took five days in which the main issue was to gather documents and screen them against the study purpose and keywords. About 53 publications were used in the study. The review took additional twelve days in which thematic analyses, evaluation, synthesis, and discussion were done. The constructs could be coded for and thematic frequencies could be generated for the study. The findings were organized into respective thematic questions. The review questions were:

a) What are the impacts of the COVID-19 pandemic on the teaching, learning, and management of educational institutions?

b) What are the institutional external and internal organs included in the education EPRRM frameworks?

c) How are the various institutional organs integrated into the education EPRRM frameworks to effect the purposes?

\section{Results and Discussion}

This section presents the review findings with thematic response rates on the impacts of COVID19 pandemic which appeared in publications made on the effects the pandemic has caused on teaching, learning, and administration of education. About nineteen (19) specific affected areas were presented in Tables 4:1, 4:2, and 4:3, each with a sufficient discussion.

\subsection{Impacts of COVID-19 Pandemic on Teaching}

The data on the impacts of COVID-19 on teaching processes in educational institutions were compiled involving five variables summarized in Table 4:1 for analysis and discussion.

Table 4:1 COVID impacts on teaching in educational institutions

\begin{tabular}{lccc} 
Impact & Frequency & Percent & Cumulative Percent \\
\hline Reduced student-student-faculty interaction & 9 & 36.0 & 36.0 \\
Disruption of the academic calendar & 4 & 16.0 & 52.0 \\
Cancellation of workshops and conferences & 2 & 8.0 & 60.0 \\
Loss of manpower & 2 & 8.0 & 68.0 \\
Iniquities in the use of online teaching resources & 8 & 32.0 & 100.0 \\
\hline Total & 25 & 100.0
\end{tabular}




\section{a) Reduced student-student-faculty interactions}

The COVID-19 emergence imposed serious impacts on the interactions required for teaching classes. From the evaluation presented in Table 4:1 on the situation, about $36 \%$ of the reviewed works (9 studies) revealed reduced interactions among students, between student and faculty members, and among faculty members themselves (Ali, 2020; Day et al., 2021; Fitzpatrick, n.d.; (Hanushek \& Woessmann, 2020; Huber et al., 2020; Jena, 2020; Msigwa, 2020; Miralles-Martínez et al., 2020; Woessmann et al., 2020). As COVID-19 cases and deaths proliferated globally in the first quarter of 2020, many tertiary institutions were shut down thereby affecting face-to-face classes (Ali, 2020). Shutting down the institutions meant for reduced chances of interactions for effective teaching. Msigwa's (2020) study on the COVID-19 impacts on education systems in Tanzania had similar findings. The immediate modality after closures, for many countries especially HICs, was to have institutions undergone sudden changes of teaching activity from the face-to-face model to virtual classrooms (Woessmann et al., 2020). However, a survey by Woessmann et al. (2020) involving 1,000 parents of school children in Germany revealed that only $6 \%$ of students could attend virtual classrooms daily while more than $67 \%$ had individual contact with their teachers less than once a week. Connected to this is a survey by Huber et al. (2020) describing the school situation in Germany, Austria, and Switzerland from the perspectives of around 7,100 participants. The participants included pupils, parents, school staff, school management, representatives of the school administration, and support systems. The survey findings indicated reduced teaching interactions. A similar situation was the case in all other affected countries. The worst cases manifested that some teachers and students had no interest in virtual classrooms. This phenomenon was verified in research by Subedi et al. (2020) on impacts of e-learning during COVID-19 among nursing students and teachers in Nepal that involved 104 respondents from 13 nursing colleges, which indicated that $80.8 \%$ of participants indicated it was not ok for them with online classes but they preferred facing people physically in schools. This could probably be due to the impossibility of conducting practical and clinical classes online or some other reasons.

Despite that, a study by Jena (2020) on the impacts of COVID-19 on the higher education system of India which used information from different authentic websites, journals, and e-contents, found that students shifted to submit the assignments, internship reports, and projects in scanned soft copies to the institution through E-mails during the lockdown. But Day et al. (2021) caution that E-mails used in countries had a natural lack of body language signs and this could impact negatively on motivation and participation. It implies that the systems of education had no well-set physical and soft infrastructures pre-established for the education emergencies which could continue classroom interactions to the online platforms. This was the case of higher education institutions in the Sub-Saharan Africa (SSA) countries. For instance, a presentation by Okereke et al. (2020) on the COVID-19 challenges of uptake of e-learning involving 35 African countries revealed that the pandemic's potential of reducing social and communication skills due to the absence of studentstudent interaction and student-teacher engagements was high. As the hits were unpredictable, the chances were continued fall of interactive teaching and learning skills (Fitzpatrick, n.d.). Institution closures were initiated at systemic and institutional levels depending on the country. For example, in Tanzania, it was the protocol of the central government to close and re-open the institutions with a pseudo-orthodox pandemic response merging religious and tradition and modern epidemiological interventions. It sounds logical that faith controlled panic and created resilient conditions which 
probably saved many lived. The ministries involved in executing the interventional programs for safety were the Ministry of Health Community Development, Gender, Elderly and Children (MoHCDGC), President's Office, Regional Administration, and Local Government Authorities (PO-RALGAs), and Security Departments which formed the tactical teams at the LGAs levels. These ensured that response and recovery practices through the "New Normal" were consistently taken by citizens at the individual level. The Tanzania MoHCDGC had the experience of dealing with outbreaks such as Anthrax in the Northern part of the country under One Health Policy, and with some skillsets being acquired through special capacity building for Rapid Response Teams (RRT) to respond to public health emergencies, including the 2018 training on Ebola (One Health in Action, 2017; WHO, 2018.). Other ministries provided physical, material, and human resources to support the response and recovery processes. However, it seems that the education department, particularly, the HLIs had inadequate or lacked the EPRRM plan ensuring advantage to teaching during COVID-19 in the first quarter of 2020.

Indeed, all processes from closing to re-opening lacked adequate engagement, coordination, and communication contingency plan. Consequently, teaching stopped and in a few circumstances was done through broadcasting channels to deliver lessons including Tanzania Broadcasting Channel (TBC), Independent Television (ITV), Upendo TV, Star TV, and Channel Ten TV. The channels were the only option available by that time because there was no prior contingency plan that could have facilitated the use of the virtual classrooms services with more interactive teaching platforms such as LMSs, M-Elimu, Socrative, Edmodo, and Moodle as well as visual panel spaces such as Zoom, Google Meet, Skype, Youtube live and WeChat. It is also true that most learners stayed idol without taking any follow-ups as most were not informed or were not motivated with watching and listening from broadcasted lessons, and others had no TV equipment set in place. However, the magnitude of this case has not yet been evaluated. Logically, the teaching processes were not motivating as there had have been no prior inclusive processes set in place as the education EPRRM framework lacked. Regarding the fact that HLIs and students would be well-financed, teaching programs would not have stopped had the EPRRM framework been there directing for virtual classroom implementation utilizing theoretical delivery and practical simulations, given the nature and level of learners. The macro-level assessment, policy development, and planning were required to guide for harmonious response among HLIs in the country in times of crises such as the COVID19 pandemic. The EPRRM contingency plan would guide for joint effort to inclusive response on emergencies, which seemed to lack serious emphasis even in HICs.

\section{b) Disruption of the academic calendar}

The COVID-19 pandemic disrupted academic terms and calendars in all levels of teaching between 2020 and 2021 in many countries. This was verified in $16 \%$ of publications reviewed (Day et al., 2021; Msigwa, 2020; Sintema, 2020; Woessmann et al., 2020) as presented in Table 4:1. The disruption was due to inevitable institutional closures as the outbreak was unfamiliar to the global community. Consequently, class works stopped in all levels of teaching (Day et al., 2021), and therefore changes in term length and daily timetable was inevitable in many countries (Msigwa, 2020; Sintema, 2020). Closing the institutions was presented to be an effective measure against viral infections and spread but most institutions were not prepared to transform to virtual classrooms. Teaching and learning activities had to be shifted to online only in a few countries involving a few institutions. This had serious negative consequences on resource investment and 
time utility. For example, after re-opening the institutions had to increase financial resources and teaching hours to cover the content prescribed in the curriculum for given academic terms and semesters. This was also the case in Tanzania. In this context, the instruction routines were heavily burdened to cover instructional contents. The contents which could have been delivered during the stay at home waited for re-opening, so could be delivered in hustles with lengthened day routines. There was a justification of the demand for the contingency plan.

c) Cancellation of local and international physical classes, conferences, and workshops The COVID-19 pandemic affected negatively the professional development of teachers and instructors. This effect scored 8\% (Jena, 2020; Msigwa, 2020). During the lockdown of countries and cities in 2020 and 2021, local and international conferences and workshops were canceled as travels and gatherings were put under legal prohibition for health safety reasons (Msigwa, 2020). There were no travels among the nations and across the continents (Jena, 2020). This had negative consequences to teachers' and instructors' activities related to teaching. The impacts could especially be experienced by HLIs' professors who could not attend cross-border activities physically during the period. This was directly correlated to reduced career opportunities. It was until the late months of 2020 when the conferences could be practices through online platforms as alternatives in some countries. The Tanzania HLIs were not exceptions for similar cases as most similar events were postponed or canceled. Canceling the workshops and conferences signified lack of contingency plan to keep on progress of the interactive teaching and learning related issues.

\section{d) Loss of manpower}

The COVID-19 pandemic caused many death incidences in a very short period after the eruption. This was verified in $8 \%$ of the reviewed articles (Table 4:1). The problem proliferated rapidly especially in countries like Italy, China, the USA, Brazil, Russia, India, Chile, Spain, Peru, and Iran (Brodeur et al., 2020; Msigwa, 2020). The death rates had increased to an estimate of 500,000 within a short period of six months across the nations by 23 June 2020 (Brodeur et al., 2020). Among the deceased were professionals in education. Teachers and instructors died just as people in other cadres and social groups did. Professionals in the medical career took significant measures to control the viral spread, though to the extent of the local capacity. However, there was no emergent interventional program to rescue the educationists and learners in most of the countries including Tanzania, built in the education system and its departments. The education machinery looked like were suddenly paralyzed leaving room for the response teams from MoHCDGC, security departments, and other stakeholders which played in far distant role to reach the education institutions' missions and operations. The education system did not have the education EPRRM contingency plan to keep its core activities running amid soaring death rates. Consequently, the management practices in institutions experienced high stake dynamism with management by objective (MBO) outweighing management by walking around (MBWA). MBWA necessitates the use of those at the operationalization level to supervise by a physical presence so that things can keep moving on smoothly. Some preexisting ethos and terms of services had to automatically transform into other forms. Particularly, issues of water, sanitary and hygiene (WASH), social distancing, and reduced mobility were more campaigned and practiced in many areas under seriously strict supervision by security departments. However, the involvement of the education departments and institutions through its core functions of teaching and learning was initially very parochial. 


\section{e) Inequities in accessing online teaching resources}

Table 4:1 also indicates that $32 \%$ percent of the reviewed publication showed inequities in accessing online teaching resources by instructors during the closedown of the education institutions (Agrawal et al., 2020; Day et al., 2021; Di Pietro, et al., 2020; Miralles-Martínez et al., 2020; Osman, 2020; Subedi et al., 2020; Tadesse \& Muluye, 2020). The gap in teacher skills, availability of physical and soft infrastructures and resources, and adaptation to online platforms to support teaching (Miralles-Martínez et al., 2020). In many cases represented by Nepal, about $14.4 \%$ of teachers and instructors were used to virtual classrooms, and among this percent, most had problems with the internet and power supply (Subedi et al., 2020). Although about $76.0 \%$ of teachers and instructors knew about online learning media, $62.5 \%$ had a negative sense that it would be difficult to control the disturbances during teaching (Subedi et al., 2020). The notion that an education EPRRM plan lacked in such countries arises from the fact that during this time there was a serious lack of use of digital technology and educational resources (Tadesse \& Muluye, 2020). An online survey involving professors in the Philippines, on their experiences in the implementation of the e-learning classrooms could reveal that COVID-19 gave the first encounter to many instructors to use the online resources for teaching, though they enjoyed it (Reyes-Chua, 2020). In many HICs, private institutions had more effective virtual learning classes than public ones with exception of European countries including Slovenia, Austria, Italy, Czechia, Poland, Romania, Estonia, Malta, and Croatia. This gap between private and public institutions manifested in Bulgaria, Greece, and Luxembourg. It was in Slovenia where a quite large gap favored public institutions (Di Pietro, et al., 2020).

Generally, teachers and instructors in most EU countries with exception of Slovenia, France, Croatia, Hungary, and Belgium were in serious need of ICT skills for teaching (Di Pietro, et al., 2020). Despite that, a study on the emergency of remote teaching at Sultan Qaboos University showed that the COVID-19 pandemic increased preferences to online programs which were about $41 \%$ rate even before the lockdown (Osman, 2020). Osman (2020) reminds us that it took over 17

years for $41 \%$ of courses to be taught in a blended format. Inequities were also evident concerning home circumstances, access to technology, and physical and mental health issues, and due to such reasons, class attendance could fall to as low as $30 \%$ initially at the University of Texas at Austin, for instance (Day et al., 2021). Moreover, the difference in gender preferences to online programs during the lockdown manifested among students from Malaviya National Institute of Technology, India (Agrawal et al., 2020). In practice, those from rural areas were more disadvantaged (Tadesse $\&$ Muluye, 2020). This situation was severe in low-income countries (LICs) including Tanzania. Had the adequate education EPRRM contingency plan been put in place, it would have directed the HLIs to use the smart equipment for virtual classes and other online resources concerning the fact that almost all of the HLIs members including students could possess facilities for that purpose.

\subsection{Impacts on Students' Learning in Educational Institutions}

The data on the impacts of COVID-19 pandemic on students learning were compiled involving ten constructs summarized in Table 4:2 for analysis and discussion. 
Table 4:2 COVID-19 effects on students' learning

\begin{tabular}{lccc} 
Effect & Sources & Percent & Cumulative Percent \\
\hline Creation of learning gap & 13 & 25.0 & 25.0 \\
Reduction of international education & 4 & 7.7 & 32.7 \\
COVID-19 skills as a hidden curriculum & 2 & 3.8 & 36.5 \\
Learners' behavioral and emotional malfunctioning & 6 & 11.5 & 48.1 \\
Social isolation & 6 & 11.5 & 59.6 \\
Lack of institutional support & 6 & 11.5 & 71.2 \\
Inequities in online learning access & 8 & 15.4 & 86.5 \\
Change in exams schedules and course grade policies & 3 & 5.8 & 92.3 \\
Malnutrition of learners in low-income societies & 2 & 3.8 & 96.2 \\
Reduced future economic returns to schooling & 2 & 3.8 & 100.0 \\
\hline Total & 51 & 100.0
\end{tabular}

\section{a) Creation of learning gap}

Based on Table 4:2, 25.0\% of the reviewed publication reported COVID-19 pandemic created a learning gap (Ali, 2020; Azevedo et al., 2020; Conto et al., 2020; Day et al., 2021; Di Pietro, et al., 2020; Espino-Díaz et al., 2020; Hanushek \& Woessmann, 2020; Huber et al., 2020; Kuhfeld et al., 2020; Msigwa, 2020; Nugroho et al., 2020; Sintema, 2020; Woessmann et al., 2020). During the close-down students were unable to attend in-person classes and a big proportion could not afford online learning programs (Ali, 2020). Students' learning was disrupted in different circumstances resulting in reduced learning, and the problem was severe to the disadvantaged students (Conto et al., 2020). In China, for example, most of the students were worried about course completion due to reduced learning pace and expected remote learning to their grades policies (Day et al., 2021). Closed schools also meant the loss of skills already acquired, upon which further learning could build (Kuhfeld et al., 2020). In some countries, exclusion manifested based on nationality and ethnicity as most of the HICs lacked an inclusive education EPRRM contingency plan. For example, migrant students were at disadvantage especially in France, Belgium, Germany, Austria, Finland, Sweden, Denmark, Spain, and the Netherlands (Di Pietro, et al., 2020) where many migrants lacked learning support (Di Pietro, et al., 2020; Hanushek \& Woessmann, 2020). The learning gap was also accompanied by increased attrition from students who were unsatisfied with the virtual learning experiences, extended learning requirements including non-affordability of tuition, and unanticipated change of life plans into other life programs including marriages due to prolonged stay at home (Msigwa, 2020). Msigwa (2020) therefore cautioned that even in wellresourced institutions enrolment forecast would be challenged, and that compensation programs were required for the learning gaps.

According to the School Barometer survey of 2020 which involved Austrian, Swiss, and German students, weekly learning time was reduced by between 4 and 8 hours during the lockdown, compared to when schools were open so that studying was less than 9 hours per week (Huber et al., 2020). The World Bank projection on the pandemic was that closures and family livelihood loss would result in an average loss of 0.3-0.9 quality-adjusted years of schooling (Azevedo et al., 2020). This projection meant reduced learning achievements that students gain during their lifetime from 7.9 to between 7.0 and 7.6 years (Azevedo et al., 2020). Closures limited access to education and the more access was limited, the greater the damage caused (Espino-Díaz et al., 2020). As students were not prepared for changes, their commitment to academics in remote learning was low 
as well (Sintema, 2020). For Germany, learning activities per day were halved from 7.4 to 3.6 hours, an estimate established from the fact that $38 \%$ of students studied for no more than two hours and $74 \%$ for no more than four hours per day (Woessmann et al., 2020). In LICs including Tanzania, the effectiveness and challenges of the learning options taken were not yet evaluated. Essentially, the situation might have had been worse than in HICs. Governments and education actors had to make plans for accelerated learning and catch-up programs to recover the learning lost (Nugroho et al., 2020). Notwithstanding such a situation and relevant interventional programs, the education EPRRM contingency plan was supposed to be put in place earlier to ensure that no learning was lost during the pandemic.

\section{b) Reduction of international education}

During the self-isolation, closures and lockdown practices, and ban of travels the rate of access to international education was reduced (Day et al., 2021; Jena, 2020; Msigwa, 2020; Sintema, 2020) This was evidenced by $7.7 \%$ of the reviewed articles. The Cambridge International AS and A Level, Cambridge AICE, Diploma, and Cambridge Pre-University examinations for May and June 2020 series were affected across countries, and the International Baccalaureate examinations as well (Ali, 2020; Jena, 2020). In India, admission, examinations, entrance tests, competitive examinations conducted by various colleges and universities were postponed (Jena, 2020). Graduate and undergraduate research projects were also affected (Msigwa, 2020). It was also revealed that in Zambia there was a drop in the performance levels due to lost contact hours (Sintema, 2020). It seems that the capacity and capability to administer learning activities and examinations through online platforms were not significantly available in many countries by that time, though some platforms such as Moodle, Socrative, and others could provide the sites for such matters. This also means that most learning activities progressed without tracking of learning progress. This situation probably was worse in most LICs like Tanzania (Msigwa, 2020). In one way, the problem was magnified by a change in the daytime as students returned to their home country. In another way, infrastructures to support remote learning were insufficient in some home towns especially for students who moved from HICs to LICs. Barriers to learning progress were especially intense to projects that required access to laboratory facilities, face-to-face interviews, participatory observations, and in particular those which needed international travel (Day et al., 2021). It is clear that for Tanzania, the place of e-spaces for conferences, meetings, and discussions was not considered in responses made to COVID-19 on the case of the education sector earlier in 2020.

\section{c) Induction learning on COVID-19 skills a hidden curriculum}

From Table 4:2, 3.8\% of the review results identified the emergence of COVID-19 skills training as a hidden curriculum. Many countries and communities focused on COVID-19 skill dissemination (Ali, 2020; Jadhav et al., 2020; Msigwa, 2020), in addition to other skillsets which people especially in the case of Rajasthan, India could acquire (Agrawal et al., 2020). The lockdown experiences paved for the aggregation of many skillsets on COVID19 and other soft skills through webinars. These skillsets were not necessarily relevant to the prescribed instructional curriculum of their enrolments. This impact on learning was particularly higher among college and university students (Jadhav et al., 2020). On the part of institutional management, it required highly skilled personnel for a temperature check and other containment programs (Msigwa, 2020). Educational experts were affected in most cases and some died of the infections (Msigwa, 2020) as they were prepared for the matters in advance. It was really clear that the education sector in many countries 
including Tanzania needed an education EPRRM contingency plan to curb the COVID-19 situation for the safety of students and the teaching staff (Ali, 2020). The education EPRRM contingency plan would be adopted and adapted in many unforeseen outbreaks and pandemics.

\section{d) Learners' behavioral and emotional malfunctioning}

The COVID-19 mortality influenced learners' behavioral and emotional malfunctioning as was evidenced by $11.5 \%$ of the reviewed publications (Table $4: 2$ ). This was the situation among nations especially at the beginning of 2020 as institutions were closed and students stayed at home (Copeland et al., 2021; Hanushek \& Woessmann, 2020; (Holshue et al., 2020) (Jena, 2020) Qiu et al., 2020; Son et al., 2020). Regarding closures, public attention was focused on the health and safety concerns of institutions, and nations experimented with alternate ways to re-open institutions. Surprisingly, Hanushek and Woessmann (2020) criticized nations as they ventured into some processes arguing that they did not consider longer-run issues including the world's economies in the far future. Their contentions conferred with regime's position in Tanzania. The outbreak, as well as unprecedented government response, had some negative psychological impact on the general public and especially on students (Holshue et al., 2020; Qiu et al., 2020). For example, the findings from emotional health and wellness study at the University of Vermont involving 675 undergraduate students indicated the possibility of COVID-related adjustments including externalizing and attention problems (Copeland et al., 2021). The pandemic season influenced a decrease in mood and wellness behaviors. A similar study using interviews on the COVID-19 impacts on students' mental health in Texas, United States of America (USA) revealed $71 \%$ of students had increased stress and anxiety (Son et al., 2020). Jena (2020) explains that anxiety among students was due to uncertainty of being promoted from one grade to another and that the situation was more magnified for those who expected graduation for employment in foreign countries as air travel was banned. The fact that the education EPRRM contingency plan was not mentioned, no mechanism to learning resilience was clear to give students confidence. This had more negative consequences as students especially in LICs could lose focus and be entertained into other life ventures including unplanned marriages and pregnancies as the case was reported in some regions of Tanzania (Daily News Paper, April 28, 2021).

\section{e) Social isolation}

Based on Table 4:2. 11.5\% of the review publications presented social isolation as a problem to students (Ali, 2020; Copeland et al., 2021; Espino-Díaz et al., 2020; Okereke et al., 2020; Prahani $\&$ Cheng, 2020; Son et al., 2020). By the end of May 2020, academic institutions and schools had have been closed in 153 countries of which 1,198,530,172 students were affected in HICs and LICs (Okereke et al., 2020). Several alternatives were used to keep them learning including online and broadcasting television strategies. Of course, many students were not able to return to in-person classes due to restrictions (Ali, 2020). They could not have opportunities for socialization and physical collaboration with peers. Even after re-opening, students were subject to the "new normal" era guided by COVID-19 control conditionality which insisted on social distancing, isolation, masking facial epithelial tissues, washing hands with running water and soaps, sanitizing (EspinoDíaz et al., 2020), and the latter vaccination. On the "new normal", Prahani and Cheng (2020) explain that social and physical distancing policies were implemented in many countries in response to COVID-19 hits. But these had serious negative impacts. In Texas USA for example, $91 \%$ of students could experience negative impacts on the living environment and lifestyles (Son 
et al., 2020). In many countries including Tanzania, conspicuous changes in infrastructures of HLIs were observed creating spaces for sanitation and sanitization, and rearrangements for on-campus social distancing, especially in venues. However, on-campus social distancing had negative consequences weighted similar to remote learning (Copeland et al., 2021).

\section{f) Lack of institutional support}

The problem of the lack of institutional support to students was presented in $11.5 \%$ of the reviewed documents in Table 4:2. There was no full integration of the ICT facilities learning programs across the countries (Ali, 2020; Copeland et al., 2021; Day et al., 2021; Di Pietro, et al., 2020; MirallesMartínez et al., 2020; Okereke et al., 2020). This is probably why transitions into online classrooms were challenged. Students needed more institutional support than ever but in real practices, the availability of faculty and transparency of institutional information was reduced (Copeland et al., 2021). Most faculty perceived it difficult to replicate the face-to-face experience through remote teaching and in most implementations were characterized by insufficient consultation time with poor lecture delivery technical affairs (Day et al., 2021). In some instances, harassment and discrimination based on the perception of a Chinese origin of the virus was a common experience for Asian faculty and students in North America (Day et al., 2021). They were subjected to access and quality use gaps based on ethnicity and origin relative to their native counterparts (MirallesMartínez et al., 2020). Many migrant students were challenged by low familiarity with the content of online learning activities with limited command of the language of use (Di Pietro, et al., 2020). In LICs including Tanzania, the notable contrast was the threat of severe resource unavailability, lack of accessibility and infrastructure, communication barriers, and social factors which prevented the uptake of online education (Okereke et al., 2020). The education EPRRM contingency plan was required to rule out for the budgetary policies in support of the sectorial responses during crises.

\section{g) Inequities in technological and online classrooms access}

From Table 4:2, 15.4\% of the reviewed publications revealed there were inequities in access and use of learning resources between students from high income and low-income families (Agrawal et al., 2020; Chetty et al., 2011; Di Pietro, et al., 2020; Espino-Díaz et al., 2020; Hanushek \& Woessmann, 2020; Sintema, 2020; Sutton Trust, n.d.; Tadesse \& Muluye, 2020; Tria, 2020; UNDP, 2020). Following COVID-19 responses, more advantaged students attended schools to adopt online learning (Tadesse \& Muluye, 2020). Students from low-income families had to conduct studies in small spaces shared with other family members, so the learning process was difficult. On this matter, Di Pietro and his colleagues (2020) reaffirmed on the 2018 PISA data in some HICs that students from high-income families accessed better digital infrastructures under teachers well equipped with digital skills than students from low-income families (Di Pietro, et al., 2020). The magnitude of this gap was larger in Belgium, Luxembourg, Estonia, Hungary, Finland, and Greece (Di Pietro, et al., 2020). Even in the USA, the gap affected negatively students from low-income areas (Chetty et al., 2020). Despite that, the majority of countries had private institutions performing better in soft resources than public ones with the exceptions of European countries such as Slovenia, Austria, Italy, Czechia, Poland, Romania, Estonia, Malta, and Croatia (Di Pietro, et al., 2020; Tadesse \& Muluye, 2020). This gap was maximum in Bulgaria, Greece, and Luxembourg (Di Pietro, et al., 2020), and in some other contexts it manifested between urban and rural area institutions (Tria, 2020). The cumulative effect was linked to parents' knowledge and skills for online learning (Espino-Díaz et al., 2020). This phenomenon alerted governments should establish 
strong contingency plans to close the "digital divide" across households, localities, and urbanizations (Hanushek \& Woessmann, 2020; Sintema, 2020).

\section{h) Change of examinations and conferences schedules}

From Table 4:2, 5.8\% of the reviewed publications revealed the changes in examination and conference schedules, and the course grade policies (Day et al., 2021; Jena, 2020; Sintema, 2020). Most of the external examinations were postponed and internal ones were canceled (Jena, 2020). This situation was negatively impacting the occupational future of students' life (Jena, 2020). Through the period, administrators in many countries were challenged by the need to revise course assignments and develop evaluation and assessment strategies that adapted to a socially distanced setting but reflecting learning objectives (Sintema, 2020). For example, at Macalester College, USA, group projects became more difficult to implement and were replaced by individual tasks, and some papers were graded based on effort rather than quality (Day et al., 2021). Accordingly, course grade policies were temporarily changed by many other universities and colleges including the Chinese University of Hong Kong, Sinclair Community College, Kennesaw State University, Okanagan College, and the University of Texas at Austin. For example, grading systems at the University of Texas at Austin were rescheduled to base on pass-fail grades in spring 2020 (Day et al., 2021). In some instances, extended time to complete courses was also allowed at Macalester, and of course, this did not resemble the case of some universities in Tanzania where day routines were extended to cover courses within short periods than usual to confer to the normal schedules. Such challenges were reported to affect more science than art disciplines (Sintema, 2020).

\section{i) Malnutrition of learners in low-income societies}

From Table 4:2, 3.8\% of the reviewed publications reported the problem of malnutrition to learners in low-income societies (Espino-Díaz et al., 2020; Son et al., 2020). During this period, a large number of students lost meals they used to receive in institutions at free or at a minimal cost (Espino-Díaz et al., 2020). This implied the hits subjected students to the problem of malnutrition at varying levels. The problem was also related to the economic consequences of increased unemployment rates which caused loss of wages and damage to productivity (Espino-Díaz et al., 2020). Generally, the COVID-19 pandemic disrupted the eating patterns and access to good quality meals by the students (Son et al., 2020). The governments' approach of providing meals to households in lock-down in many HICs and LICs including Rwanda had a limitation for supply in abundance as per households' needs. There were no budgets in internal treasuries to feed citizens who had no recommended diets. For regimes like that of Tanzania, it was taken not possible to adopt the lockdown of cities and households with such reasons of budgetary bottlenecks.

\section{j) Reduced future economic returns to education due to learning losses}

The COVID-19 pandemic had immediate social and economic impacts on many countries. It imposed students to reduced future economic returns to schooling (Azevedo et al., 2020; Hampf et al., 2017; Hanushek \& Woessmann, 2020). On this conception, an extension was made in focus from the near-term impact of business closures on unemployment longer-run issues borne to the students' learning losses (Hanushek \& Woessmann, 2020). Accordingly, the scholarly analyses showed prolonged loss would follow students into the labor market to create adverse economic outcomes for the students and their nations in the future (Hanushek \& Woessmann, 2020; Hanushek \& Woessmann, 2008). Accordingly, the loss would have been on the order of $3 \%$ lower career 
earnings to students if they immediately returned to 2019 performance levels, and for nations, the effect could have been $1.5 \%$ lower GDP if education systems were slow to return to normal levels of performance.

Moreover, little was known about the effectiveness and consequences of learning at home for the entire students population and related impacts on skill development (Hanushek \& Woessmann, 2020). But data on learning lost in Germany for example, plus many hours spent by students on $\mathrm{TV}$, computer games, and mobile phones for passive activities during their stay at home implied more negative consequences on future economic returns to students. The national economies that grow with a less skilled labor force grow at lower rates (Hanushek \& Woessmann, 2020). From comparisons of learning on tests designed to track performance over time, students on average learn about one-third (1/3) of a standard deviation per school year (Hanushek \& Woessmann, 2020). Accordingly, for example, the loss of one-third of a school year of learning would correspond to about $11 \%$ of a standard deviation of lost test results (i.e., 1/3 x 1/3). To understand the economic losses from school closures, the estimated relationship between standard deviations in test scores and individual incomes from a recent international study is used by adult PISA" survey conducted in 32 HICs between 2011 and 2015 involving a sample of the population aged 16 to 65 (Hampf et al., 2017). The relationship between labor-market incomes and test scores across 32 countries revealed that the economic rewards to higher skills vary among countries:

...Workers in Singapore are estimated to receive 50\% higher income if they have one standard deviation higher test scores, the typical worker in Greece gains just $14 \%$ more income with one standard deviation higher test scores. For the United States, the comparable return to skill is $27 \%$, and for the average across all sampled countries, it is $23 \%$. Looking at the corona-induced learning losses associated with one-third of a year closure, the pooled estimates indicate that current students will suffer a $2.6 \%$ loss in income across their entire careers. The estimated losses for this one-third-year closure exceed 3\% in the USA and reach 5.6\% in Singapore (Hanushek \& Woessmann, 2020:11).

Among the G.20 nations, China and USA are expected to experience the corona-induced learning loss worth $\$ 15542$ and $\$ 14197$ for 1/3 year learning, and $\$ 30636$ and $\$ 27982$ for 2/3 year learning, respectively (Hanushek \& Woessmann, 2020). Importantly, these relationships provide estimates of the impact of skill differences across the entire work-life (Azevedo et al., 2020; Hanushek \& Woessmann, 2020). This means the maximum learning loss for one-third a year experienced in China had more than the equivalent of the average future income loss of 36,034,127TZS per student in LICs including Tanzania accruing to the period of March to June 2020, and 71,029,566TZS if were to extend to $2 / 3$ a year in 2020 (Hanushek \& Woessmann, 2008). The education EPRRM contingency plan was necessary to provide remedial practices to curb such learning losses through immediate response to any form of breakdown during skill development cycles.

\subsection{Impacts on Administration of Education}

The data on the impacts of COVID-19 pandemic on administration of education were compiled involving four constructs summarized in Table 4:3 for analysis and discussion. 
Table 4:3 COVID-19 Impacts on the administration of education

\begin{tabular}{lccc} 
Impacts & Frequency & Percent & Cumulative Percent \\
\hline Impediments on academic research and & 4 & 14.3 & 14.3 \\
professional development & 5 & 17.9 & 32.1 \\
Reduced employment opportunities & 4 & 14.3 & 46.4 \\
Challenged internal and external assessments & 15 & 53.6 & 100.0 \\
Subjection to online teaching without capacity & 28 & 100.0
\end{tabular}

\section{a) Impediments on academic research and professional development}

Based on Table 4:3, 15.4\% of the reviewed publications presented the fact that COVID-19 pandemic resulted in inhibition of scholarly publications from the faculty (Ali, 2020; Day et al., 2021; Jena, 2020; Radecki \& Schonfeld, 2020). Researchers couldn't travel and work together with others nationally and internationally. Some joint research and project works were complicated to complete due to the inaccessibility of some scientific laboratory services (Jena, 2020). At the end of 2020 to 2021, webinars and online conferences became popular methods for sharing expertise among academicians around the globe but could not provide real spaces for laboratory research (Jena, 2020). Consequently, there was a global case of significant drops in scholarly production and publishing (Radecki \& Schonfeld, 2020). The fact that staff members were directed to work from home (Ali, 2020), justifies the presentation by Radecki and Schonfeld (2020) that the female researchers were more affected than their male counterparts as they resumed home responsibilities. Online meetings to supervise students and conducting defense for theses as well as manuscripts presentations were challenging to schedule, less effective, and required prior approval (Day et al., 2021). Most of challenges were borne to the fact that countries especially the LICs including Tanzania had no prior education EPRRM contingency plan to provide massive services during the crisis.

\section{b) Unemployment and redundancy of teachers}

Table 4:3 showed that $17.9 \%$ of the reviewed publications presented problems of unemployment and teacher redundancy due to the COVID-19 pandemic (Day et al., 2021; Espino-Díaz et al., 2020; Hanushek \& Woessmann, 2020; Jena, 2020; UNDP, 2020). Faculty members in precarious employment were more vulnerable to termination (Day et al., 2021). Of course, the capacities of the institutions to pay workers had to fall due to the absence of students especially in private systems that depended on user fees for running. In some countries productivity and wages only declined (Espino-Díaz et al., 2020). Moreover, some instructors had to work in occupations with lower skill requirements (Hanushek \& Woessmann, 2020). They could not get a job outside their home country due to various restrictions as the case was in India (Jena, 2020). In Tanzania the case was different as especially for public sector as employment and salary security was ensured for the in-service teachers though no new recruitment was until the second half of 2021. However, some private schools had to reduce workers and others reduced salaries or both teachers and teachers' salaries.

\section{c) Challenged internal and external assessments as administrative responsibility}

Table 4:3 shows that $14.3 \%$ of the reviewed publications identified the internal and external assessments as challenges to the administration and management of the HILs during the COVID19 related closures and lockdown (Day et al., 2021; Jena, 2020; Sintema, 2020; Okereke et al., 
2020). It was technically difficult to revise course assignments and develop evaluation and assessment strategies that adapted to online and distance delivery (Day et al., 2021). Accordingly, the technology for identity verification and monitoring of work environments for remote teaching and examinations was not easily tested and implemented due to concerns of internet connections and computer availability. That is probably why most of the external examinations were postponed and all the internal assessments canceled (Jena, 2020). This had wider negative impacts on a dropin institutional performance (Okereke et al., 2020; Sintema, 2020). However, this would have been a political concern of the education EPRRM contingency plan to address the situation in advance.

\section{d) Running online management and teaching without capacity}

From Table 4:3, 53.4\% of the reviewed papers showed that transition into online teaching and learning activities subjected the administrations and managements to run activities under limited and inadequate digital, physical and human resources (Agrawal et al., 2020; Chetty et al., 2011; Day et al., 2021; Di Pietro, et al., 2020; Jena, 2020; Miralles-Martínez et al., 2020; Msigwa, 2020; OECD, 2020; Okereke et al., 2020; Owusu-Fordjour et al., 2020; Prahani \& Cheng, 2020; (Subedi et al., 2020) (Tadesse \& Muluye, 2020) (Tria, 2020). Some instructional lectures were delivered from creative home studios while others not, but in most cases, they were low technical affairs which could also be attributed to the low skills of administrators, managers, and implementers to digital technologies (Day et al., 2021; Miralles-Martínez et al., 2020). The same relatively low familiarity with the content of online learning activities manifested among parents and other family members where students stayed during the season (Di Pietro, et al., 2020). For example, around $65 \%$ of students in the UK had the possibility of accessing online learning platforms (OECD, 2020), but their learning progress suffered a strong decline during the crisis (Chetty et al., 2020). Simple technologies including the use of scanned copies of learning materials during internships and project report through email during the lockdown for Covid-19 (Jena, 2020; Okereke et al., 2020) were the most common practices. There was poor evaluation and developmental framework, and severe lack of supporting infrastructure including computer-assisted technologies such good quality laptops, smartphones, tablets, etc. (Okereke et al., 2020). The simulation of laboratory settings was tried and adapted by some HICs to ensure the delivery of practical course content to students but rarely was the case in LICs (Okereke et al., 2020). Moreover, about $88.8 \%$ of students' parents in SSA could not facilitate students access and use of the internet at home to learn while about $73.8 \%$ did not have orientation from their teachers on the use of e-learning platforms before the school closed down (Owusu-Fordjour et al., 2020; Prahani \& Cheng, 2020; Tria, 2020), as the majority of instructors and administrators lacked the skillsets and were not competent with ICT tools (Tadesse \& Muluye, 2020). In addition, it was evident that only $14.4 \%$ of students were used to the internet for an online class (Subedi et al., 2020), but the other $85.6 \%$ were not. Instructors were faced with challenges of enrolled students who lacked necessary ICT infrastructures including computers for online classes (Tadesse \& Muluye, 2020). As some of the institutions were faced with a cut in budgets it was even more difficult to purchase the equipment (Msigwa, 2020). They were essentially not prepared for the emergence.

\section{Conclusion and Recommendations}

The COVID-19 Pandemic had serious negative impacts on the systems of education globally and domestically. It alerted the policy planners and decision-makers that a new era may emerge of 
change in social, economic, cultural, and historical dimensions to affect a human race. It presented a context to think that some disease occurrences can harm life similar to other natural catastrophes such as floods, earthquakes, volcanic eruptions, famine, war, and drought. Though may not take down or corrode physical structures like buildings but may take down life and if not controlled may wipe out the population in the same way it happened in about major five big extinctions including that of dinosaurs and dodo in the earth's history. This is particularly why there has been a major global concern toward the current situation. The global health partners through World Health Organization (WHO) prioritized more effort on the development of vaccines for the Coronavirus in addition to other emergent measures. However, the articulation of the practices did not theorize on the long-term impacts of closing education institutions. The importance of transforming physical classrooms to soft virtual classrooms, and integrating both was not prioritized. As such, the responses lacked fiscal and soft resources and infrastructure to keep education programs running smoothly. In this context, there existed a gap between governments of HICs and LICs, students from advantaged and disadvantaged backgrounds for the possibility of the students to continue and maintain learning pace through virtual classrooms as the institutions closed. The major reason was most countries had no contingency plan to respond to emergencies. It has been found therefore for countries like Tanzania that the education EPRRM contingency plan is mandatory, that should be updated with time.

\section{Recommendations}

a) A detailed evaluation of the socio-economic consequences of the COVID-19 Pandemic in an extended period in the Tanzanian context was required in order to make informed decisions.

b) The education EPRRM contingency plan relevant to HLIs should be put in place to avoid unnecessary learning breakdown in case of emergencies.

c) The reports and claims on students' dropouts, pregnancies and early and unplanned marriage required quantification of the magnitudes, and their relationships with violence and child exploitation in households and neighborhoods where students stayed during the COVID-19 closures.

\section{References}

Agrawal, S., Sharma, N., \& Singh, M. (2020). Employing CBPR to understand the well-being of higher education students during COVID-19 lockdown in India. SSRN Electronic Journal. https://doi.org/10.2139/ssrn.3628458

Ali, W. (2020). Online and remote learning in higher education institutes: A necessity in light of COVID-19 Pandemic. Higher Education Studies, 10(3), 16-25. https://doi.org/10.5539/hes.v10n3p16

Azevedo, J. P., Hasan, A., Goldemberg, D., Iqbal, S. A., \& Geven, K. (2020). Simulating the potential impacts of COVID-19 school closures on schooling and learning outcomes: A set of global estimates. World Bank. https://doi.org/10.1596/1813-9450-9284 
Brodeur, A., Gray, D., Islam, A., \& Bhuiyan, S. J. (2020). A literature review of the economics of COVID-19. IZA - Institute of Labor Economics: Discussion Paper Series, 63. https://www.nber.org/wp_covid19.html.

Chetty, R., Friedman, J. N., Hilger, N., Saez, E., Schanzenbach, D. W., \& Yagan, D. (2011). How does your kindergarten classroom affect your earnings? Evidence from Project Star. The Quarterly Journal of Economics, 126(4), 1593-1660. https://doi.org/10.1093/qje/qjr041

Conto, C. A., Akseer, S., Dreesen, T., Kamei, A., Mizunoya, S., \& Rigole, A. (2020). COVID-19: Effects of school closures on foundational skills and promising practices for monitoring and mitigating learning loss. Office of Research - Innocenti Working Paper, WP 202013.

Copeland, W. E., McGinnis, E., Bai, Y., Adams, Z., Nardone, H., Devadanam, V., Rettew, J., \& Hudziak, J. J. (2021). Impact of COVID-19 pandemic on college student mental health and wellness. Journal of the American Academy of Child \& Adolescent Psychiatry, 60(1), 134-141. https://doi.org/10.1016/j.jaac.2020.08.466

COVID-19 Impacts: School Shutdown. (n.d.). Sutton Trust. Retrieved 5 May 2021, from https://www.suttontrust.com/our-research/covid-19-and-social-mobility-impact-brief/

Day, T., Chang, I.-C. C., Chung, C. K. L., Doolittle, W. E., Housel, J., \& McDaniel, P. N. (2021). The immediate impact of COVID-19 on postsecondary teaching and learning. The Professional Geographer, 73(1), 1-13. https://doi.org/10.1080/00330124.2020.1823864

Daily News Paper, April 28, 2021. Retrieved on May 6, 2021, from https://www.dailynews.co.tz/dashboard/magazeti?kibali=eyJ0eXAiOiJqd3QiLCJhbGciOi JIUzI1NiJ9.eyJjb25zdW1lcktleSI6IiVFTkNLRVkIJUVOQ0tFWSUIRU5DS0VZJSVFTk NLRVklIiwidXNlcklkIjo5NjUwLCJjb3Jwb3JhdGUiOm51bGwsImlzc3VlZEF0IjoiMjAy MS0wNS0xMlQxMzoyMjowMCswMDAwliwidHRsIjo4NjQwMH0.ihLkzOawvUM340 GNUvF2NH3NRnZ6GGC6WzCLBRI-fFc

Di Pietro, G., Biagi, F., Costa, P., Karpiński, Z., \& Mazza, J. (2020). The likely impact of COVID19 on education: Reflections based on the existing literature and recent international datasets. Publications Office. https://data.europa.eu/doi/10.2760/126686

Espino-Díaz, L., Fernandez-Caminero, G., Hernandez-Lloret, C.-M., Gonzalez-Gonzalez, H., \& Alvarez-Castillo, J.-L. (2020). Analyzing the impact of COVID-19 on education professionals. Toward a paradigm shift: ICT and Neuro-education as a binomial of action. Essay, 12(14), 1-10. https://doi.org/10.3390/su12145646

Fitzpatrick, M. (n.d.). Teaching, teachers' pensions, and retirement across recent cohorts of college graduate women. NBER Working Paper Series, Working Paper 22698. http://www.nber.org/papers/w22698

Galabawa, J. C. J. (2001). Perspectives in educational management and administration. H. R. Consult

Geren, B. (n.d.). Motivation: Chinese theoretical perspectives. Journal of Behavioral Studies in Business, 10. https://www.aabri.com/manuscripts/10692.pdf 
Hampf, F., Wiederhold, S., \& Woessmann, L. (2017). Skills, earnings, and employment: Exploring causality in the estimation of returns to skills. Large-Scale Assessments in Education, 5(1), 12. https://doi.org/10.1186/s40536-017-0045-7

Hanushek, E. A., \& Woessmann, L. (2008). The role of cognitive skills in economic development. Journal of Economic Literature, 46(3), 607-668. https://doi.org/10.1257/jel.46.3.607

Hanushek, E. A., \& Woessmann, L. (2020). The economic impacts of learning losses. OECDBetter Policies for Better Lives. https://www.oecd.org/education/The-economic-impactsof-coronavirus-covid-19-learning-losses.pdf

Holshue, M. L., DeBolt, C., Lindquist, S., Lofy, K. H., Wiesman, J., Bruce, H., Spitters, C., Ericson, K., Wilkerson, S., Tural, A., Diaz, G., Cohn, A., Fox, L., Patel, A., Gerber, S. I., Kim, L., Tong, S., Lu, X., Lindstrom, S., ... Washington State 2019-nCoV Case Investigation Team. (2020). First case of 2019 Novel Coronavirus in the United States. The New England Journal of Medicine, 382(10), 929-936. https://doi.org/10.1056/NEJMoa2001191

Huber, S. G., Günther, P. S., Schneider, N., Helm, C., Schwander, M., Schneider, J., \& Pruitt, J. (2020). COVID-19 und aktuelle herausforderungen in schule und bildung (COVID-19 and current challenges in schools and education). The New England Journal of Medicine, 382(10), 929-936. https://doi.org/DOI: 10.1056/NEJMoa2001191

Jadhav, V. R., Bagul, T. D., \& Aswale, S. R. (2020). COVID-19 era: Students' role to look at problems in education system during lockdown issues in Maharashtra, India. International Journal of Research and Review, 7(5), 328-331. http://www.ijrrjournal.com/

Jena, P. K. (2020). Impact of Covid-19 on higher education in India. International Journal of Advanced Education and Research, 5(3), 77-81. http://www.alleducationjournal.com/

Kispál-Vitai, Z. (2016). Comparative analysis of motivation theories. International Journal of Engineering and Management Sciences, 1(1), 1-13. https://doi.org/10.21791/IJEMS.2016.1.25

Kroth, M. (2007). Maslow-Move Aside! A heuristical motivation model for leaders in career and technical education. Journal of Industrial Teacher Education, 44(2), 5-36. https://files.eric.ed.gov/fulltext/EJ830477.pdf

Kuhfeld, M., Soland, J., Tarasawa, B., Johnson, A., Ruzek, E., \& Liu, J. (2020). Projecting the potential impacts of COVID-19 school closures on academic achievement. EdWorking Paper, No.20-226. https://doi.org/10.26300/CDRV-YW05

Luthans, F., \& Stewart, T. I. (1977). A general contingency theory of management. The Academy of Management Review, 2(2), 181-195. . https://digitalcommons.unl.edu/managementfacpub/179

Maslow, A. H. (1943). A theory of human motivation. Psychological Review, 50, 370-396. http://www.yorku.ca/dept/psych/classics/author.htm 
Miralles-Martínez, P.; Gómez-Carrasco, C.J.; Sánchez-Ibañez, R. (2020). Ask Me Questions and I Will Tell You What They Assess and Teach. An Analysis of Social Sciences Exams in the 5th and 6th Grade of Primary School. Aula Abierta, 42, 83-89

Msigwa, F. M. (2020). COVID-19 Pandemic and its implications on education systems in Tanzania. International Journal of Science and Research, 9(9), 167-171. https://doi.org/10.21275/SR20828103844

Nugroho, Dita, et al., (2020).COVID-19: How are Countries Preparing to Mitigate the Learning Loss as Schools Reopen? Trends and emerging good practices to support the most vulnerable children.' Innocenti Research Briefs, 2020, <https://EconPapers.repec.org/RePEc:ucf:inores:inores1119>, accessed 14 April 2021.

OECD (2020) 'Learning Remotely when Schools Close: How Well Are Students and Schools Prepared? Insights from PISA' https://read.oecd ilibrary.org/view/?ref=127_127063iiwm328658\&title=Learning-remotely-when-schools-close

Okereke, M., Williams, A. E., Emmanuella, N. C., Ashinedu, N. U., \& Mairaj, M. W. (2020). COVID-19: Challenges affecting the uptake of e-learning in pharmacy education in Africa. The Pan African Medical Journal, 35(2), 1-3. https://doi.org/10.11604/pamj.supp.2020.35.2.23910

One Health in Action. (2017). One Health Zoonotic disease Prioritization for Multi-Sectoral engagement in Tanzania. Ministry of Health Community Development, Gender, Elderly and Children.

Osman, M. E. (2020). Global impact of COVID-19 on education systems: The emergency remote teaching at Sultan Qaboos University. Journal of Education for Teaching, 46(4), 463471. https://doi.org/10.1080/02607476.2020.1802583

Owler, K., \& Morrison, R. L. (2015). What makes work enjoyable and motivating for Learning Advisors in Aotearoa-New Zealand? Association of Tertiary Learning Advisors Aotearoa/New Zealand Journal, 1(1), 16-33. https://doi.org/10.26473/atlaanz.2015.1.1/002

Owusu-Fordjour, C., Koomson, C. K., \& Hanson, D. (2020). The impact of COVID-19 on learning-The perspective of the Ghanaian student. European Journal of Education Studies, 7(3), 88-101. https://doi.org/10.5281/ZENODO.3753586

Prahani, B. K., \& Cheng, T.-H. (2020). "New Normal" in learning and teaching. Studies in Learning and Teaching, 1(2), 63-65. https://doi.org/10.46627/silet.v1i2.41

Qiu, J., Shen, B., Zhao, M., Wang, Z., Xie, B., \& Xu, Y. (2020). A nationwide survey of psychological distress among Chinese people in the COVID-19 epidemic: Implications and policy recommendations. General Psychiatry, 33(2), e100213. https://doi.org/10.1136/gpsych-2020-100213

Radecki, J., \& Schonfeld, R. (2020). The impacts of COVID-19 on the research enterprise. Ithaka S+R. https://doi.org/10.18665/sr.314247 
Reyes-Chua, E. (2020). The status of the implementation of the e-learning classroom in selected higher education institutions in Region IV-A amidst the COVID-19 crisis. Journal of Critical Reviews, 7(11). https://doi.org/10.31838/jcr.07.11.41

Sintema, E. J. (2020). Effect of COVID-19 on the performance of Grade 12 students: Implications for STEM Education. Eurasia Journal of Mathematics, Science and Technology Education, 16(7), 1-6. https://doi.org/10.29333/ejmste/7893

Son, C., Hegde, S., Smith, A., Wang, X., \& Sasangohar, F. (2020). Effects of COVID-19 on college students' mental health in the United States: Interview survey study. Journal of Medical Internet Research, 22(9), 1-6. https://doi.org/10.2196/21279

Subedi, S., Nayaju, S., Subedi, S., Shah, S. K., \& Shah, J. M. (2020). Impact of E-learning during COVID-19 Pandemic among nursing students and teachers of Nepal. International Journal of Science and Healthcare Research, 5(3), 68-76. http://www.ijshr.com/

Suleiman, N., Abba, M., \& Yahaya, L. (2018). Explored and critique of contingency theory for management accounting research. Journal of Accounting and Financial Management, 4(5), 40-50. www.iiardpub.org

Tadesse, S., \& Muluye, W. (2020). The impact of COVID-19 Pandemic on education system in developing countries: A review. Open Journal of Social Sciences, 8(10), 159-170. https://doi.org/10.4236/jss.2020.810011

Tan, S. K. (2013). Herzberg's two-factor theory on work motivation: Does it work for todays environment? Global Journal of Commerce and Management Perspective, 2(5), 18-22.

TCRA. (2017). Quarterly communications statistics report: April - June 2017. Dar es Salaam, Tanzania. Retrieved from https://www.tcra.go.tz/images/documents/telecommunication/TelCom-Statistics-June2017.pdf

Tria, J. Z. (2020). The COVID-19 Pandemic through the lens of education in the Philippines: The new normal. International Journal of Pedagogical Development and Lifelong Learning, 1(1), ep2001. https://doi.org/10.30935/ijpdll/8311

Vero, E. (2017). The importance of motivation in an educational environment. Formazione \& Insegnamento, 15(1), 57-66.

https://www.google.com/search?q=Vero\%2C+E.+(2017).+The+importance+of+motivati on+in+an+educational+environment.+Formazione+\%26+Insegnamento $\% 2 \mathrm{C}+15(1) \% 2 \mathrm{C}$ $+57-$

66\&rlz=1C1CHZL_enTZ909TZ909\&oq=Vero\%2C+E.+(2017).+The+importance+of+m otivation+in+an+educational+environment.+Formazione+\%26+Insegnamento\%2C+15(1 \%2C+57-66\&aqs=chrome..69i57.1209j0j15\&sourceid=chrome \&ie=UTF-8

WHO (n.d.). Tanzania launches training for national rapid response teams with focus on Ebola. WHO | Regional Office for Africa. Retrieved 6 May 2021, from https://www.afro.who.int/news/tanzania-launches-training-national-rapid-responseteams-focus-ebola

Woessmann, L., Vera, F., Elisabeth, G., Philipp, L., Katharina W. and Larissa, Z. (2020), "Bildung 
in der Coronakrise: Wie haben die Schulkinder die Zeit der Schulschließungen verbracht, und welche Bildungsmaßnahmen befürworten die Deutschen? [Education in the corona crisis: How did the schoolchildren spend the time the schools were closed and which educational measures do the Germans advocate?]". Ifo Schnelldienst, 73(9). Retrieved on $8^{\text {th }} \quad$ April 2021 from file:///C:/Users/Reuben\%20Bihu/Desktop/Meta\%20analysis/Woessmann-etalbildungsbarometer-corona.pdf

World Bank and GFDRR (2019). Education sector recovery: Disaster recovery guidance series. https://www.researchgate.net/publication/330354352

Yudhvir, M., \& Sunita, M. (2012). Employee's motivation: Theories and perspectives. Asian Journal of Multidimensional Research, 1(2), 56-64. http://www.tarj.in 